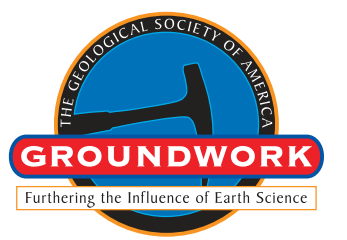

\title{
Assembling Laurentia-Integrated Theme Sessions on Tectonic Turning Points
}

Michael L. Williams, Dept. of Geosciences, University of Massachusetts, Amherst, Massachusetts 01003, USA, mlw@geo.umass.edu; Dawn A. Kellett, Geological Survey of Canada-Atlantic Division, Natural Resources Canada/Government of Canada, 1 Challenger Drive, Dartmouth, Nova Scotia B2Y 4A2, Canada, dawn.kellett@canada.ca; Basil Tikoff*', Dept. of Geoscience, University of WisconsinMadison, 1215 W. Dayton Street, Madison, Wisconsin 53706, USA, basil@geology.wisc.edu; Steven J. Whitmeyer, Dept. of Geology and Environmental Science, James Madison University, 801 Carrier Drive, MSC 6903, Harrisonburg, Virginia 22807, USA, whitmesj@jmu.edu

The North American continent records the evolution of tectonic processes and tectonic environments from the earliest Archean to modern times. The continent hosts a rich Archean (and possibly Hadean) record, at least three great Proterozoic orogenic belts, and a wide range of Phanerozoic tectonic, sedimentary, and paleobiologic environments, including active plate boundaries. In many ways, Laurentia (ancestral North America) might be thought of as the prototypical continent, with a little - if not a lotof everything. With its long record of changing tectonic settings, supercontinent cycles, and geologic outcomes, one question persists: Does Laurentia preserve a record of fundamental, relatively short duration changes in tectonic processes on Earth, or rather, a gradually changing configuration of continents in a slowly evolving plate tectonic system? The resolution of this question requires a continent-wide perspective on tectonics through time, and it requires the integration of many fields of geoscience. One way to approach the question is to ask (1) what is the holistic geological character of Laurentia at particular times in Earth history?; and (2) what are the apparent controlling factors at those times, from mantle dynamics to plate interactions, to surface weathering, to biological evolution?

The GSA 2020 Annual Meeting provides an opportunity to address the tectonic evolution of Laurentia and the evolution of tectonic processes in general as an international geoscience community. A meeting-long series of topical sessions have been organized that will focus on important times - which we call "Turning Points"-in the assembly, disassembly, modification, and growth of North America (Fig. 1). These sessions will be headlined by a Pardee Symposium, which will provide an overview of the tectonic evolution of Laurentia and an introduction to the concept of key "Turning Points." Seven related topical sessions, under the general heading "Assembling Laurentia," will span the GSA meeting. Each session will scrutinize key periods in the long history of the continent when the character, rate, or style of tectonic processes may have changed or when the plate tectonic process itself may have changed in some fundamental way. The ultimate goal is to identify potential drivers for,

and the broader implications of, these changes, and to widen the scope of investigation beyond a particular boundary or regional geological event to the scale of Laurentia itself. The time slices for the topical sessions are as follows (with brief explanations from each session proposal):

\section{8-2.5 Ga: Neoarchean Crust Formation and Cratonization}

The Neoarchean time interval was the last, great episode of Precambrian crust formation prior to the Paleoproterozoic assembly

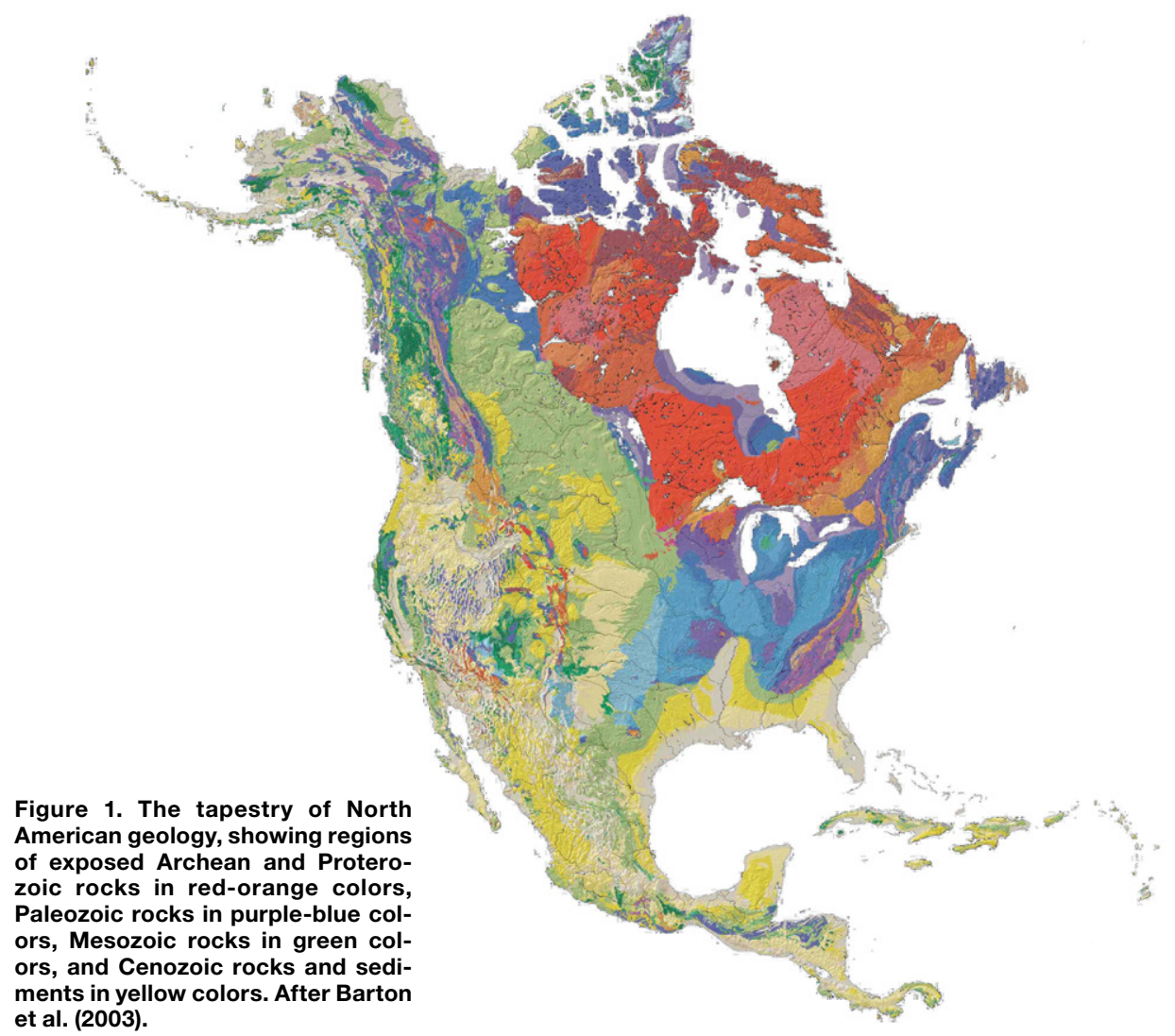

GSA Today, v. 30, https://doi.org/10.1130/GSATG459GW.1. Copyright 2020, The Geological Society of America. CC-BY-NC.

*Corresponding author. 
of Laurentia. These continental nuclei form Laurentia's core.

\section{9-1.7 Ga: Turning Points in Paleoproterozoic Tectonic Evolution}

The Paleoproterozoic time interval saw the formation of the first recognizable passive margins, formation and accretion of oceanic crust, arcs, back-arc basins, foreland basins, and other environments arguably characteristic of modern plate tectonics.

\section{5-1.4 Ga: GEON 14 Enigmas and Advances in Understanding the Crustal Evolution and Paleogeography of the Early Mesoproterozoic North America}

Mesoproterozoic Laurentia was dominated by an Andean-scale active, but still very enigmatic margin, spanning $\sim 5000 \mathrm{~km}$, from eastern Canada to the southwestern United States and Mexico.

\section{2-1.0 Ga: Mesoproterozoic to} Early Neoproterozoic Tectonic Evolution of Laurentia and Its Role within the Supercontinent Rodinia

The late Mesoproterozoic to early Neoproterozoic spans the rise and fall of the Grenville orogen at the center of the supercontinent Rodinia, the formation of the Midcontinent Rift, and the initial breakup of Rodinia.

\section{0-540 Ma Neoproterozoic to} Cambrian Rifting and Continental Margin Evolution during Breakup of

\section{Rodinia and Pannotia}

The Neoproterozoic to Cambrian time interval marked the breakup of Rodinia and Pannotia, and formation of the margins of Laurentia. The Neoproterozoic was also a time of profound climatic and biologic change, which may have been related to these changing tectonic conditions.

\section{0-340 Ma Paleozoic Mobile Margins}

The Silurian-Carboniferous closure of the Iapetus and Rheic oceans and the progressive growth of the Appalachian-Caledonian orogen along eastern Laurentia marked the onset of a series of tectonic events that propagated around Laurentia between the Devonian and Permian.
190-70 Ma Growth of the Western Continental Margin by Subduction, With or Without Terrane Accretion

This 190-70 Ma time slice saw the formation of the wide North America Cordillera and the opening of the Gulf of Mexico, involving a number of processes, including extension, shortening, lateral translation, subduction, magmatism, metamorphism, erosion, and sedimentation.

The choice of time slices is based, at least in part, on the current literature and recent meeting symposia that have highlighted new insights and interpretations, as well as unresolved questions about Laurentia's geologic history. The selection of particular time slices and the duration of the time windows will certainly be debated, but it is hoped that the discussion will articulate critical questions or outstanding problems and foster future collaboration and innovation across the geological and geophysical research communities. One aim is to gather momentum for developing new tools for opensource, widely available, collaborative integration of time-slice data sets across geologic disciplines and across the continent. As indicated previously, we hope to distinguish times when Laurentia's plate tectonic setting led to major changes in tectonic style from times when the controlling tectonic processes themselves may have shifted.

Two or three session proposers/organizers-including Canadian, U.S., and Mexican researchers - have volunteered to chair and coordinate the individual topical sessions. The goal is to solicit the broadest range of researchers, research areas, and research disciplines (including sedimentology, structural geology, petrology, geophysics, geobiology, etc.) in order to capture all aspects of the evolving continent (including now external Laurentian fragments and traces) and its consequent implications during a particular time slice. The Pardee Symposium and the seven associated topical sessions have been endorsed by several GSA Divisions as well as the Mineralogical Society of America.

There are two reasons that this is a particularly opportune time to take such an adventurous approach at a national meeting. First, the conclusion of the EarthScope project in the U.S., the LITHOPROBE project in Canada, and many other more regional geologygeophysics collaborations make this an appropriate time to think about the tectonic record in the broadest possible terms. Geophysical data sets are now widely available, and workers are processing and integrating the data in new ways to gain insight into 3D implications of surface observations. Actualistic models of plumes, drips, slabs, slab tears, mantle wind, Moho variation, and discontinuities at all levels of the crust, lithosphere, and deeper mantle can be integrated with the surface record in order to build a truly 4D model of Earth tectonics.

The second reason is more specifically related to the current time and environment in which we are living - itself a distinct "Turning Point." As we write this article, we are all sequestered in our homes in the hope that we can help mitigate the current pandemic threat. We are also unsure whether the 2020 GSA Montréal meeting will happen, and if so, in what form. This gathering of many geoscience disciplines under the framework of Laurentia's evolution will be a celebration of the creative, collaborative, and international efforts that have made the scientific advances possible. Plate tectonics is our unifying theory, and as such, inherently involves all the fields of the geological sciences. Moreover, understanding the evolution of Laurentia has always required an international effort, although most critically engaging people located in North America. We are not just "in it together," but with respect to Laurentia, we are "on it together." Our individual research programs have always benefitted from the research of colleagues, working in other places and on different problems in their respective subfields, leading us to insights and discoveries that would have otherwise been out of reach. It has become more important than ever to assemble (whether in person or virtually), make new connections across our fields, and together establish our collective understanding of the place we all share.

\section{REFERENCE CITED}

Barton, K.E., Howell, D.G., and Vigil, J.F., 2003, The North America Tapestry of Time and Terrain: U.S. Geological Survey, Geologic Investigations Series I-2781.

Manuscript Received 3 Apr. 2020

ReVISED MANUSCRIPT RECEIVED 15 Apr. 2020

MANUSCRIPT ACCEPTED 24 APr. 2020 